\title{
La escala Atlacholoaya: Una propuesta para la evaluación de la personalidad antisocial.
}

\author{
José Martín Amenabar Beitia ${ }^{1}$ \\ Universidad del País Vasco
}

Manuscrito recibido el 01 de diciembre de 2011 / Publicado el 17 de febrero de 2012

\section{RESUMEN}

En el presente trabajo se da a conocer una escala, con preguntas dicotómicas, que ha sido creada para detectar los rasgos psicopáticos entre la población reclusa. Fue aplicada a 68 internos de la penitenciaria de Atlacholoaya (México), condenados por robo con violencia, por secuestro, por violación y/o por homicidio, a quienes también se les administró el MCMI-II (la fuente de validación externa) así como otros dos nuevos cuestionarios, con preguntas de opción múltiple, uno de los cuales se centra en los actos delictivos cometidos y el otro en las circunstancias familiares y sociales.

La escala Atlacholoaya tiene una confiabilidad (de acuerdo al alfa de Cronbach) de 0,928 y una correlación (según la formulación de Spearman) de 0,672 con la dimensión antisocial del MCMI-II, en lo que pueden considerarse como resultados satisfactorios, o más bien prometedores, tratándose como se trata de una novedosa prueba diagnóstica en fase de estudio piloto.

Palabras clave: Violencia delictiva, trastorno antisocial de la personalidad, psicopatía, reclusos, escala, cuestionarios, MCMI-II.

\footnotetext{
${ }^{1}$ Correspondencia autor: josemartin.amenabar@ehu.es
} 


\begin{abstract}
In the present work it is been given to know a scale, with dichotomical questions, which has been created to detect the psychopathical characteristics among the inmate population. It was applied to 68 convicts of the penitentiary of Atlacholoaya (Mexico), condemned for aggravated robbery, kidnapping, rape and/or homicide, to whom were also administered the MCMI-II (the external source of validation) as well as two more new questionnaires with multiple choice questions, one of them focused in the committed criminal acts and the other one focused in the familiar and social circumstances.

The Atlacholoaya scale has a reliability (according to Cronbach's alpha) of 0,928 , and a correlation (according to the Spearman's formulation) of 0.672 with the antisocial dimension of the MCMI-II, in which they can be considered like satisfactory results, or rather promising, as we are talking here of an innovative test in the phase of the pilot study.
\end{abstract}

Keywords: Criminal violence, antisocial personality disorder, psichopathy, inmates, scale, questionnaires, MCMI-II.

\title{
Introducción
}

La violencia, según la Organización Mundial de la Salud (OMS), constituye un problema de salud pública que puede prevenirse y disminuirse en sus efectos, de la misma manera que ha logrado hacerse en las complicaciones del embarazo, en las enfermedades infecciosas y en otros problemas. Para ello es necesario contar con datos científicos, que se han de obtener desde muchas y diversas disciplinas, por ejemplo, desde la psicología, con objeto de «facilitar información detallada acerca de la víctima o el agresor y sus antecedentes, actitudes, comportamientos y posible participación anterior en actos de violencia» (Organización Panamericana de la Salud, 2003, p. 9).

En el campo de la psicología es sabido que gran número de episodios delictivos y/o violentos son cometidos por gente con trastorno antisocial de la personalidad (TAP), un trastorno que, con base en los criterios del DSM-IV-TR, radica en «un patrón 
general de desprecio y violación de los derechos de los demás, que comienza en la infancia o el principio de la adolescencia y continúa en la edad adulta» (American Psychiatric Association, 2003, p. 784), debiendo cumplirse por lo menos tres de los siguientes ítems: trasgresión de las normas sociales; deshonestidad; impulsividad; irritabilidad y agresividad; conductas de riesgo; irresponsabilidad; falta de remordimientos.

Los sujetos antisociales «se encuentran representados en los criminales reincidentes, delincuentes sexuales, traficantes de drogas, estafadores, mercenarios, políticos corruptos, abogados sin ética, tiburones de las finanzas, vendedores sin escrúpulos, terroristas, líderes de sectas religiosas» (Caballo y López Torrecillas, 2004, p. 109).

Cabe destacar que la condición antisocial o psicopática no implica necesariamente la comisión de comportamientos delictivos y/o violentos ${ }^{2}$, puesto que hay psicópatas que viven en el marco de la legalidad, aunque también es cierto que a estos sujetos no les preocupan apenas las consecuencias que sus acciones tienen en los demás; si para conseguir sus objetivos o satisfacciones tienen que pasar por encima de los otros, dañarlos, o incluso eliminarlos, no será la conciencia moral la que los detenga sino, en todo caso, la consideración de que sus intereses personales se vean afectados. Desde esta concepción radicalmente egocéntrica de la vida, el arrepentimiento que muestran cuando son apresados y están encarcelados no es tanto por haber causado sufrimiento a las víctimas y sus allegados sino más bien por el hecho de que ya no pueden disfrutar de la libertad. Que los otros sufran o padezcan por ellos raramente les conmueve.

Los sujetos con personalidad antisocial o psicopática, debido a la grave carencia empática que les caracteriza, incapacitados como están para entablar relaciones profundas y duraderas, y ajenos al conocimiento de la confianza y la lealtad, son dados a explotar y dominar a la gente. Y lo peor para quienes interactúen con ellos es que generalmente persisten en esta forma de proceder, pues no hay una culpa socializante por la cual recapaciten y sientan la necesidad de reparar en lo posible el daño cometido; es por eso que, a partir del momento en que consideren difícil acceder al poder y a la

\footnotetext{
${ }^{2}$ La formulación diagnóstica aquí referida «es un tema controvertido, desde el momento que unos autores señalan como aspecto importante la alteración de la personalidad, mientras que otros señalan la existencia de conductas desviadas» (López Miguel y Núñez Gaitán, 2009, p. 11).
} 
gratificación inmediata desde el marco de la legalidad, es predecible que lo traten de conseguir saltándose las normas.

Sostiene Hare (2000) que la psicopatía es un indicador de reincidencia y violencia futura. En la misma línea, Patrick afirma que «la investigación empírica ha puesto de manifiesto la estrecha relación que existe entre la psicopatía y el comportamiento violento en los delincuentes varones» (Patrick, 2000, p. 109), por lo que «debemos esforzarnos en identificar a los psicópatas del resto de criminales violentos» (McCord, 2000, p. 209). A este respecto, con ánimo de lograr el propósito mencionado, pueden utilizarse, entre otros, los siguientes cuestionarios ${ }^{3}$ :

1) Cuestionario de Agresión (AQ) (Buss y Perry, en la adaptación española de Andreu, Peña y Graña, 2002). Consta de 29 ítems que se estructuran en torno a cuatro sub-escalas: agresividad física, agresividad verbal, ira y hostilidad.

2) Escala del Trastorno Antisocial de la Personalidad de Aluja (ETAPA) (Aluja, 1986, anexo en 1991). Consta de 47 ítems que hacen referencia a comportamientos antisociales de la infancia y de la adultez. Toma como criterios de evaluación los del DSM-III.

3) Inventario Clínico Multiaxial de Millon-II (MCMI-II) (Millon, en la adaptación española de Ávila y Jiménez, 1998). Consta de 175 ítems, a través de los cuales se evalúan 13 dimensiones o patrones de personalidad: 1) Esquizoide, 2) Fóbica, 3) Dependiente, 4) Histriónica, 5) Narcisista, 6A) Antisocial, 6B) Agresivo/sádica, 7) Compulsiva, 8A) Pasivo-agresiva, 8B) Auto-destructiva, S) Esquizotípica, C) Límite, P) Paranoide.

\footnotetext{
${ }^{3}$ En el proceso de evaluación psicológica existen distintas modalidades de recogida de información (cuestionarios, entrevistas y observación directa), cada una de las cuales presenta sus ventajas y desventajas. Cuando el propósito que guía al investigador es conocer las características de un amplio grupo de población, las ventajas de los cuestionarios (en cuanto a rapidez y economía de esfuerzo) se hacen evidentes.
} 


\section{Planteamiento del problema}

En este apartado se van a considerar los alcances y las limitaciones de cada uno de los instrumentos considerados, y su capacidad diagnóstica.

Con respecto al Cuestionario de Agresión ha de destacarse que mediante el mismo solamente es posible evaluar algunos aspectos del trastorno antisocial de la personalidad (impulsividad, irritabilidad, agresividad), por lo que, no disponiendo de información sobre otras variables, no hay manera de saber hasta qué punto un sujeto agresivo se conduce por un patrón general de desprecio y violación hacia los derechos de los demás.

Para la delimitación del conjunto de características antisociales o psicopáticas ha sido diseñada la ETAPA (Aluja), a través de la cual podemos evaluar la impulsividad, la agresividad, la transgresión de las normas sociales, la deshonestidad, la irresponsabilidad y la comisión de ciertas conductas de riesgo, centrándose la atención, de acuerdo a lo planteado en el DSM-III, en la desviación social o criminalidad, en lo que puede considerarse como una «perspectiva limitada de lo antisocial como "criminal"» (Millon, 1998a, p. 447).

Lo enunciado en el DSM-III precisaría, en opinión de Millon, una reformulación sustentada en criterios que «fueran más consonantes con el formato de rasgos de la personalidad empleados en las otras categorías diagnósticas del Eje II» (Ibídem, p. 461), aunque eso no se habría concretado con mucho éxito en la siguiente edición, pues «el DSM-IV contiene sólo cambios modestos» (Ibídem, p. 461). Es por tal motivo que Millon (1998a), tratando de subsanar algunas de las deficiencias del DSM en la aproximación al individuo antisocial o psicopático, distingue las siguientes características clínicas: expresivamente impulsivo e interpersonalmente irresponsable (a nivel comportamental), cognitivamente desviado, autoimagen autónoma $\mathrm{y}$ representaciones objetales degradadas (a nivel fenomenológico), mecanismos de impulsividad-actuación y organización indisciplinada (a nivel intrapsíquico) y estado de ánimo insensible (a nivel biofísico).

Si hay un cuestionario a destacar en la evaluación de la psicopatía y otros trastornos de la personalidad es el MCMI, un instrumento de diagnóstico sumamente valioso, usado tanto en la práctica clínica como en la investigación, que con sus tres versiones o ediciones (MCMI-I, MCMI-II y MCMI-III) está «en constante proceso de 
evolución y mejora para recoger los adelantos más significativos del conocimiento» (Millon, 1998b, p. 13).

Sugiere el creador del MCMI que «los investigadores pueden construir escalas para "entidades" clínicas como el deterioro neurológico, implicaciones psicosomáticas, potencial suicida, disfunciones sexuales, impulsos delictivos, propensión a accidentes y otras muchas» (Millon, 1998b, p. 144). Es en este sentido que durante la presente investigación se plantea la pertinencia de crear cuestionarios a partir de los cuales podamos ahondar en las actitudes, motivaciones y circunstancias biográficas de quienes se adentran en la violencia delictiva y, al mismo tiempo, podamos estar en condiciones de discernir a aquellos sujetos con personalidad psicopática de los que no son así (tomándose en cuenta para su delimitación, a propuesta de Millon, los niveles fenomenológico, intrapsíquico y biofísico, además del nivel comportamental), puesto que el trabajo psicoterapéutico y de reintegración social a plantear con cada persona en cuestión dependerá de su forma de ser y de relacionarse, esto es, de su configuración caracterológica. De lo contrario, si no sabemos reconocer las características de personalidad que son indicadoras de elevada predisposición a la violencia y la reincidencia (recordemos a este respecto lo señalado por Hare, Patrick o McCord), podemos caer en la ingenuidad de creer que las propuestas de cambio que han resultado eficaces, y hasta exitosas, con unos sujetos lo serán con todos.

\section{Método}

Los cuestionarios creados para esta investigación son los siguientes:

— «Puntos de Vista»o «Atlacholoaya» ${ }^{4}$, que a través de 114 ítems dicotómicos está diseñado para detectar las actitudes y opiniones de los reclusos.

— «Sucesos de la Vida», que con 20 ítems de opción múltiple (junto con una ficha demográfica) sirve para conocer la influencia de determinados episodios biográficos en la forma de ser y de relacionarse.

\footnotetext{
${ }^{4}$ De entre los tres nuevos instrumentos es éste, en tanto que es presentado como eje principal del artículo, el que se da a conocer también con el nombre que se designa al lugar donde se llevó a cabo la investigación.
} 
— «Actos Ilícitos», que con 15 ítems de opción múltiple se centra en la carrera delictiva.

A la hora de conformar los cuestionarios se ha partido del conocimiento criminológico adquirido en una investigación anterior, de tipo cualitativo, consistente en la realización de historias de vida con reclusos que habían cometido delitos violentos, abordándose con ellos los más diversos temas (historia familiar, infancia, carrera delictiva, situación penitenciaria, sexualidad, opiniones sobre sociedad y religión, etc.), lo que supuso la oportunidad de acceder a una relación privilegiada y conocer de cada uno de ellos sus sentimientos, sus emociones así como su percepción de los otros y de sí mismo (véase al respecto el caso Oruan, en Amenabar, 2003). No obstante, uno de los inconvenientes de esta propuesta metodológica es la gran cantidad de tiempo ${ }^{5}$ que se requiere con cada individuo, y no sólo eso, sino que además surgen serias dificultades para poder discernir entre las características sui géneris y aquellas otras que son compartidas. Es por tal motivo que, asumiendo el reto de recabar la información que sobre sus vidas pudieran ofrecer un número apreciable de reclusos, y además en relativamente poco tiempo, aun cuando no desde la profundidad de las entrevistas, se ha optado por la elaboración de los tres cuestionarios, en lo que dicho de paso supone la complementación de una metodología cualitativa con una metodología cuantitativa.

Con respecto al cuestionario «Puntos de Vista», cabe destacarse lo siguiente:

1) Está centrado en la evaluación de la personalidad antisocial.

2) La mayor parte de las frases, si no todas, que se incluyen como ítems se inspiran o basan en lo que ciertos victimarios de características psicopáticas habían referido y comentado durante el proceso de entrevistas en profundidad de la mencionada investigación anterior (véase al respecto el caso Oruan, en Amenabar, 2003).

\footnotetext{
${ }^{5}$ A algunos reclusos se les visitó y entrevistó una sola vez, a otros a lo largo de unas 10 sesiones, a otros durante 20, 30 o muchas más. En ocasiones las sesiones duraban 45 minutos; en otras ocasiones 1 hora, 1 hora y media, 2 horas o incluso más tiempo. Todo ello dependía de muchas circunstancias, a veces ajenas, otras veces no, a las voluntades del entrevistador y del entrevistado.
} 


\section{Participantes}

Los tres nuevos instrumentos, además del Inventario Clínico Multiaxial de Millon (MCMI), concretamente el MCMI-II ${ }^{6}$, se aplicaron a una muestra de internos del $\mathrm{CERESO}^{7}$ de Atlacholoaya (México) que habían sido condenados por uno o varios delitos violentos: robo con violencia, secuestro, violación y/u homicidio.

A los reclusos se les invitó a participar en la investigación, en agosto de 2004, con arreglo a las siguientes premisas:

1) Total voluntariedad y libertad, no habiendo para los reclusos ni premio ni castigo por el hecho de participar.

2) Confidencialidad de la información.

3) Planteada únicamente por el investigador, alguien ajeno al ámbito carcelario, con objeto de evitar recelos sobre el uso de los datos. De hecho, ciertos reclusos llegaron a comentar que habitualmente contestaban con falsedades en las pruebas administradas por los psicólogos de la penitenciaría, pues temían que los resultados fueran utilizados para clasificarlos en un módulo u otro o bien para considerar la conveniencia de otorgarles beneficios penitenciarios.

Por exigencia de las autoridades la aplicación de las pruebas con algunos de los internos, concretamente con los del área de Máxima Seguridad, tuvo que ser individual mientras que con otros fue grupal. De un total de 126 sujetos a los que se hizo llamar, todos ellos condenados por robo con violencia, secuestro, violación y/u homicidio (de acuerdo a los datos facilitados por las autoridades), 57 rehusaron participar en la investigación y en otro caso, habiendo comenzado con las pruebas, se decidió suspender su aplicación hacia la mitad del primer cuestionario, debido a las serias dificultades que (relacionadas con su bajo coeficiente intelectual) presentaba el sujeto para entender el

\footnotetext{
${ }^{6}$ Ávila asegura que el MCMI-II es «un instrumento más útil para el clínico español que su sucesor» (Ávila, 1997, p. 6). De manera semejante, Jiménez Gómez y Sánchez Crespo sostienen que el MCMI-II «es uno de los mejores instrumentos de evaluación de la personalidad empleados en la actualidad para valoraciones forenses, incluso siendo preferido a la versión MCMI-III» (Jiménez Gómez y Sánchez Crespo, 2003, p. 224).

${ }^{7}$ CERESO: Centro de Readaptación Social.
} 
contenido de los ítems. Fueron, por tanto, 68 los reclusos a quienes se aplicaron las distintas pruebas, aunque varios de ellos no quisieron cumplimentar el cuestionario «Actos Ilícitos», pues negaban haber cometido los delitos (violentos) que se les imputaban. Se ha de comentar también que no pudo contarse con el MCMI-II de 9 internos, bien porque, siendo la última prueba en aplicarse, 4 de ellos decidieron no hacerla por sentirse ya cansados (algo bastante comprensible, pues el tiempo precisado desde la presentación de la propuesta de participar en la investigación hasta la finalización de todas las pruebas podía oscilar entre 1 hora y media y 2 horas y media) o bien porque 5 de ellos no completaron adecuadamente dicha prueba (a veces por no entender bastantes de las preguntas que se les formulaba y en otras ocasiones por responder de tal forma que los primeros resultados invalidaban la posibilidad de continuar con posteriores análisis).

\section{Procedimiento}

Con los datos recabados a partir de la aplicación de los cuatro instrumentos, se han llevado a cabo las siguientes tareas:

1) El análisis descriptivo de la población objeto de estudio, que hace referencia a los datos sociodemográficos, criminológicos, biográficos y relacionales más relevantes.

2) El rediseño de la escala «Puntos de Vista» o «Atlacholoaya» (en referencia al lugar donde se desarrolló la investigación), que supone la selección de aquellos ítems del listado original que son más significativos y que finalmente sirven para medir lo que se pretende medir (lo que se conoce como validez, utilizándose en este caso el MCMI-II como prueba de contraste), además de resultar consistentes para las mediciones (lo que se conoce como confiabilidad, aplicándose en este caso el alfa de Cronbach). 


\section{Resultados}

\section{Análisis descriptivo de la población objeto de estudio}

A continuación se van a reseñar los datos más importantes que se han obtenido a través de los cuestionarios «Sucesos de la Vida»y «Actos Delictivos».

Los 68 participantes en la investigación son hombres de nacionalidad mexicana. De ellos el 41,8\% tiene entre 31 y 40 años, el 39,4\% ha cursado estudios de primaria, en el $50 \%$ de los casos fue cuidado durante la infancia por sus padres, en el $83 \%$ de los casos es el único delincuente de su familia y el 43,8\% lleva en prisión entre 6 y 10 años. Por otra parte, el $29,9 \%$ de los reclusos, siendo adulto, ha golpeado o maltratado físicamente a los niños y el $34,3 \%$ ha golpeado a las mujeres. En lo que respecta a la historia delictiva (de acuerdo a lo manifestado por los propios internos, habiendo 23 de ellos que niegan su participación en los delitos imputados), contamos con los siguientes datos: Robo con Violencia (24 de 45 reclusos); Secuestro (19 de 45 reclusos); Violación (13 de 45 reclusos); Homicidio (33 de 45 reclusos); 1 Tipo DE Delito (16 de 45 reclusos); 2 Tipos de Delitos (16 de 45 reclusos); 3 Tipos de Delitos (11 de 45 reclusos); 4 Tipos DE Delitos (2 de 45 reclusos). De todas formas, la información aportada por los internos no es coincidente con la facilitada por la Dirección del CERESO de Atlacholoaya, según la cual todos los participantes en la investigación (los 68), y no solamente los 45 que así lo admiten, habrían incurrido en uno o varios tipos de delitos violentos.

Los actos ilícitos los habrían llevado a cabo algunos sujetos en grupo (el 38,5\%), otros individualmente (el 32,7\%) y en un tercer caso se alternó la acción individual con la intervención grupal (el 28,8\%). El 34\% tenía más de 18 años cuando cometió su primer delito, que para la mayoría (para un 68,5\%) habría sido el robo sin violencia.

Cabe destacar que desde la vivencia de algunos sujetos la comisión de delitos va ligada con la inquietud de buscar y experimentar EMOCIONES FUERTES. Así lo es para el $29,6 \%$, aunque la motivación principal sea para el 50\% obtener dinero, para el $14,8 \%$ radica en disfrutar del poder y para el 7,4\% en vengarse de la gente (NOTA: En este ítem, puesto que varios de los reclusos señalaron, y así podían hacerlo, varias respuestas, la suma de porcentajes supera el 100\%). Pero independientemente del elemento que conduce a actuar criminalmente, llama la atención que entre los participantes de la presente investigación al 41,5\% la comisión de los delitos le 
generara, ya sea circunstancialmente (al 26,4\%) o habitualmente (al 15,1\%), una especie de adicción, esto es, la necesidad de reencontrarse con sensaciones vivificantes.

Es sabido que ciertas DROGAS «reducen el control inhibitorio de la amenaza, los sentimientos de culpa, y neutralizan el miedo a agredir» (Garrido, Stangeland y Redondo, 1999, p. 503). En este sentido, al consumirlas, al 28,4\% de los reclusos se le activa a veces su lado violento y al 7,5\% siempre le sucede eso; por otra parte, al 22,4\% le aumenta en ocasiones el apetito sexual y al 19,4\% siempre le ocurre tal cosa. Estos diversos efectos y sus porcentajes (el surgimiento de la violencia en un total del 35,9\% y el incremento de la libido en un total del 41,8\%) nos indican la importancia de la ingesta de alcohol y/o drogas en la aparición de la conducta delictiva violenta. A este respecto, es reseñable que el $77,6 \%$ de los internos reconoce haber tomado habitualmente alcohol y/o drogas, en cuyo caso la edad de inicio más frecuente en el consumo (en el 37,3\% de los casos) ha sido entre los 16 y 20 años. De todos modos, debemos tener en cuenta que el 47,2\% nunca estaba bebido ni drogado en el momento de actuar delictivamente.

Otra variable a considerar en la violencia delictiva es la CULPA PROYECTADA, puesto que por el hecho de hacer sufrir a la(s) víctima(s) y su(s) respectiva(s) familia(s), el $38,9 \%$ se arrepintió mucho tiempo después de haber cometido el daño, el 22,2\% ha sentido una culpa pasajera o superficial (como si la culpa fuera más bien de carácter cognoscitivo y no emocional) y el 5,6\% nunca se ha sentido culpable. Únicamente el 33,3\% se arrepintió desde el principio. En cambio, debido a la situación que padecen sus propios familiares como consecuencia de haber delinquido, el $77,4 \%$ se siente culpable y el $17 \%$ se siente así a veces, un porcentaje total (el 94,4\%) que es muy superior al manifestado desde el principio (el 33,3\%) o incluso tiempo después (el 38,9\%) para con las víctimas y sus familias (el 72,2\% en total). Ello concuerda con el hecho de que es más frecuente el arrepentimiento (en el 42,6\% de los casos) frente a ciertos errores que hayan implicado ingresar en prisión, que el arrepentimiento por haber dañado a la gente (en el 35,2\% de los casos); otros reclusos manifiestan cierta ambigüedad, pues el 18,5\% está arrepentido por haber dañado a la gente así como por haber cometido errores, mientras que el 3,7\% no está arrepentido de nada.

El MALTRATO INFANTIL aparece de forma importante entre la población carcelaria, pues al 56\% su padre o figura sustituta le ha golpeado y al $74,2 \%$ su madre o 
figura sustituta. Además, al $23,1 \%$ su padre o figura sustituta lo ha maltratado psicológicamente y al 25,8\% su madre o figura sustituta. Observamos que la madre ejerce ambos tipos de maltrato (físico y psicológico) en mayor medida que el padre y a pesar de ello su valoración es mejor, ya que el 93,9\% de los reclusos sentía amor por ella siendo niño y el 95,5\% le manifiesta amor en la actualidad mientras que hacia el padre el 65,2\% sentía amor por él siendo niño y el 80,3\% le manifiesta amor en la actualidad. En definitiva, y así queda ratificado cuando el 89,4\% asegura haberse sentido querido en la casa, priman los sentimientos amorosos hacia ambas figuras parentales. Lo aquí apuntado resulta un tanto paradójico o contradictorio, en la medida que el maltrato no parece repercutir (por lo menos a nivel consciente) en los lazos afectivos. Como si se pensara que, por momentos, los adultos no tienen otro remedio que recurrir a los golpes y a las recriminaciones para corregir o gobernar la conducta de los niños; de hecho, el 69,7\% de los reclusos justifica (el 56,1\% a veces y el 13,6\% siempre) que los padres golpeen a sus hijos. Tal vez la ausencia de resentimiento o animadversión para con los padres se acompaña de malestar hacia la gente en general, como si lo no reconocido o no expresado para con unos se traspasara a los otros. La transformación de víctima en victimario se daría precisamente en aquellos sujetos que reprimen el dolor o sufrimiento padecido (Miller, 1998), como así ha podido ocurrir entre los participantes de esta investigación.

\section{Rediseño de la escala Atlacholoaya}

Partiendo del listado original (114 ítems), y siguiendo la formulación estadística de Spearman, se han correlacionado todos sus ítems con la dimensión antisocial del MCMI-II, en la que por cierto ha puntuado el 52,5\% de la población objeto de estudio, teniéndose en cuenta que para «crear una nueva escala más válida que el anterior instrumento de medición, se debería pretender obtener correlaciones entre 0,3 y 0,7 » (Lamprea y Gómez-Restrepo, 2007, p. 345) y que en el momento de aplicar la Chicuadrado el grado de significación de cada valor sea menor a 0,05 .

Como puede verse a continuación, en la tabla 1, una vez conocidos los datos correspondientes a las correlaciones de Spearman y de la Chi-cuadrado, el listado final consta de 39 ítems, en la mayoría de los cuales (en 32) la RESPUESTA ANTISOCIAL O PSICOPÁTICA supone mostrar acuerdo con la frase en cuestión mientras que en otros casos (en 7) supone mostrar desacuerdo. 


\section{TABLA 1}

\begin{tabular}{|c|c|c|c|c|}
\hline ÍTEMS & $\begin{array}{l}\% \text { de } \\
\text { resp. }\end{array}$ & $\begin{array}{l}\text { Resp. } \\
\text { psicop. }\end{array}$ & $\begin{array}{l}\text { Correl. } \\
\text { MCMI }\end{array}$ & $\begin{array}{l}\text { Chi-cuad. } \\
\text { MCMI }\end{array}$ \\
\hline 1) Necesito emociones fuertes para vivir. & 20,6 & sí & 0,371 & 0,031 \\
\hline 2) Normalmente mantengo la calma cuando me llevan a contraria. & 14,7 & NO & 0,374 & 0,014 \\
\hline 3) Siento lástima por el sufrimiento de la gente. & 10,4 & NO & 0,384 & 0,008 \\
\hline 4) Cuando alguien ofrece resistencia en un asalto y, como consecuencia de ello, resulta herido & & & & \\
\hline $\begin{array}{l}\text { o muerto, él mismo es el culpable de lo ocurrido. Eso le pasa por valorar más su dinero que } \\
\text { su propia vida. }\end{array}$ & 73,5 & sí & 0,336 & 0,002 \\
\hline $\begin{array}{l}\text { 5) Hay que dar golpes para evitar ser el que los recibe. Solamente hay dos opciones: ser } \\
\text { víctima o, por el contrario, el victimario. Y yo prefiero ser el que golpea. }\end{array}$ & 25,4 & sí & 0,388 & 0,011 \\
\hline 6) A lo largo de la vida he necesitado alcohol o drogas para escapar de la rutina. & 17,9 & sí & 0,445 & 0,020 \\
\hline 7) He crecido con rencor, con odio. & 41,2 & sí & 0,457 & 0,020 \\
\hline 8) La mayoría de la gente tiene un corazón de hielo; la gente está fría emocionalmente. & 35,8 & sí & 0,369 & 0,024 \\
\hline 9) Debido a la vida que he llevado, tal vez tendría que haber muerto hace tiempo. & 52,2 & sí & 0,437 & 0,004 \\
\hline 10) El que sufre una desgracia lo tiene merecido. Algo habrá hecho para merecerse eso. & 23,5 & sí & 0,443 & 0,017 \\
\hline 11) Cuando la gente me hace enojar, a veces respondo con golpes. & 44,1 & sí & 0,543 & 0,001 \\
\hline $\begin{array}{l}\text { 12) Cuando la gente me hace enojar, habitualmente respondo con agresiones verbales (por } \\
\text { ejemplo, insultos). }\end{array}$ & 38,2 & sí & 0,666 & 0,000 \\
\hline 13) Tengo confianza en la gente. & 45,6 & NO & 0,501 & 0,005 \\
\hline 14) Si mi pareja se arregla y se pone guapa, lo hace para engañarme y ponerme los cuernos. & 7,4 & sí & 0,322 & 0,026 \\
\hline 15) Respeto a la autoridad. & 8,8 & NO & 0,329 & 0,026 \\
\hline 16) Estoy de acuerdo con la ley del Talión; ojo por ojo y diente por diente. & 23,5 & sí & 0,349 & 0,026 \\
\hline 17) Algunas miradas me incomodan mucho, como si quisieran retarme o hacerme de menos. & 47,1 & sí & 0,466 & 0,002 \\
\hline 18) Estoy contento con la persona que soy. & 26,9 & NO & 0,547 & 0,004 \\
\hline 19) Mucha gente trata de humillarme. & 58,8 & sí & 0,544 & 0,000 \\
\hline 20) Cuando me aburro, me siento muy mal, incluso angustiado. & 48,5 & sí & 0,365 & 0,050 \\
\hline 21) La mayoría de la gente roba, viola o mata. & 43,3 & sí & 0,509 & 0,000 \\
\hline 22) Disfruto cuando alguien es golpeado o está sufriendo. & 7,4 & sí & 0,379 & 0,026 \\
\hline $\begin{array}{l}\text { 23) La mayoría de las personas que he conocido y que han formado parte de mi vida han sido } \\
\text { buenas. }\end{array}$ & 7,4 & NO & 0,336 & 0,026 \\
\hline $\begin{array}{l}\text { 24) Mis debilidades están ocultas, guardadas como secretos, incluso para la gente más cercana } \\
\text { y familiar. }\end{array}$ & 60,3 & sí & 0,592 & 0,000 \\
\hline $\begin{array}{l}\text { 25) Si alguien me humilla o me hace sentir menos, estoy dispuesto a golpearlo e incluso a } \\
\text { atentar contra su vida. }\end{array}$ & 20,6 & sí & 0,435 & 0,031 \\
\hline 26) La mujer es peligrosa, ya que trata de controlar y manipular al hombre. & 42,6 & sí & 0,572 & 0,000 \\
\hline $\begin{array}{l}\text { 27) Vivimos en un mundo tan violento y corrupto que a veces pienso que la mejor salida es el } \\
\text { suicidio. }\end{array}$ & 11,9 & sí & 0,427 & 0,038 \\
\hline 28) Los individuos que representan a la ley son despreciables. & 41,2 & sí & 0,435 & 0,009 \\
\hline 29) Mucha gente me ha humillado y despreciado. & 57,4 & sí & 0,497 & 0,000 \\
\hline $\begin{array}{l}\text { 30) Si confías en la gente, y te das a conocer tal como eres, se aprovecharán de ti y te harán } \\
\text { daño. }\end{array}$ & 52,9 & sí & 0,485 & 0,006 \\
\hline 31) Sólo me preocupa lo que me ocurre a mí; nadie más me interesa. & 19,1 & sí & 0,426 & 0,009 \\
\hline 32) Siento la necesidad de hacer daño a la gente. & 9,0 & sí & 0,392 & 0,026 \\
\hline 33) Hay que matar a muchas personas que sobran y son perjudiciales en la sociedad. & 17,6 & sí & 0,332 & 0,018 \\
\hline 34) Los remordimientos son característicos de la gente débil. & 44,8 & sí & 0,369 & 0,046 \\
\hline $\begin{array}{l}\text { 35) Cuando alguien se mete conmigo está jugando con fuego, está arriesgando su vida, pues } \\
\text { yo estoy dispuesto a matarlo si se da el caso. }\end{array}$ & 25,0 & sí & 0,492 & 0,002 \\
\hline 36) La gente me ve como una persona fría e insensible; creen que nada me afecta. & 53,0 & sí & 0,415 & 0,012 \\
\hline 37) La gente me desprecia. & 35,3 & sí & 0,478 & 0,007 \\
\hline 38) Mis compañeros son fieles, son leales. & 67,2 & NO & 0,520 & 0,001 \\
\hline 39) El mundo en que vivimos es fundamentalmente violento y corrupto; es un infierno. & 76,1 & sí & 0,374 & 0,016 \\
\hline
\end{tabular}

En las siguiente tabla, aparecen las puntuaciones ofrecidas por los 68 internos en la escala Atlacholoaya y su grado de coincidencia diagnóstica con el MCMI-II. 


\begin{tabular}{|c|c|c|c|c|}
\hline CASO & $\begin{array}{l}\text { Tipos de delitos } \\
\text { aceptados }\end{array}$ & $\begin{array}{c}\text { Puntuación } \\
\text { en Atlacholoaya }\end{array}$ & $\begin{array}{c}\text { Antisocial } \\
\text { en Atlacholoaya }\end{array}$ & $\begin{array}{l}\text { Antisocial } \\
\text { en el MCMI }\end{array}$ \\
\hline 1) & 3 & 31 & Sí & Sí \\
\hline 2) & 2 & 18 & Sí & Sí \\
\hline 3) & 2 & 6 & No & No \\
\hline 4) & 1 & 0 & No & No \\
\hline 5) & 3 & 12 & No & No \\
\hline 6) & 1 & 5 & No & No \\
\hline 7) & 1 & 21 & Sí & No \\
\hline 8) & 2 & 17 & Sí & Sí \\
\hline 9) & 2 & 14 & No & Sí \\
\hline 10) & 2 & 31 & Sí & Sí \\
\hline 11) & 3 & 24 & Sí & No hace el test \\
\hline 12) & 2 & 9 & No & No \\
\hline 13) & 3 & 26 & Sí & Sí \\
\hline 14) & 3 & 29 & Sí & No hace el test \\
\hline 15) & 1 & 18 & Sí & No \\
\hline 16) & 3 & 25 & Sí & Sí \\
\hline 17) & 4 & 33 & Sí & Sí \\
\hline 18) & 3 & 21 & Sí & Errores en el test \\
\hline 19) & 1 & 10 & No & No \\
\hline 20) & 1 & 14 & No & No \\
\hline 21) & 1 & 22 & Sí & Sí \\
\hline 22) & 1 & 33 & Sí & Sí \\
\hline 23) & 3 & 22 & Sí & Sí \\
\hline 24) & 2 & 8 & No & Errores en el test \\
\hline 25) & 2 & 11 & No & No \\
\hline 26) & 2 & 12 & No & No hace el test \\
\hline 27) & 3 & 7 & No & Errores en el test \\
\hline 28) & 2 & 6 & No & No \\
\hline 29) & 2 & 12 & No & Sí \\
\hline 30) & 1 & 19 & Sí & Sí \\
\hline 31) & 2 & 11 & No & Sí \\
\hline 32) & 1 & 3 & No & No \\
\hline 33) & 2 & 15 & Sí & Errores en el test \\
\hline 34) & 2 & 21 & Sí & Sí \\
\hline 35$)$ & 4 & 17 & Sí & Sí \\
\hline 36$)$ & 2 & 12 & No & Sí \\
\hline 37) & 1 & 28 & Sí & Sí \\
\hline 38) & 3 & 14 & No & Sí \\
\hline 39) & 1 & 12 & No & Sí \\
\hline 40) & 3 & 6 & No & No \\
\hline 41) & 1 & 1 & No & No \\
\hline 42) & 1 & 26 & Sí & Sí \\
\hline 43) & 1 & 5 & No & No \\
\hline 44) & 2 & 18 & Sí & Errores en el test \\
\hline 45) & 0 & 9 & No & Sí \\
\hline 46) & 0 & 4 & No & No \\
\hline 47) & 1 & 17 & Sí & Sí \\
\hline 48) & 0 & 9 & No & No \\
\hline 49) & 0 & 6 & No & No hace el test \\
\hline 50) & 0 & 4 & No & No \\
\hline 51) & 0 & 2 & No & No \\
\hline 52) & 0 & 15 & Sí & Sí \\
\hline 53) & 0 & 14 & No & No \\
\hline 54) & 0 & 11 & No & No \\
\hline 55$)$ & 0 & 2 & No & No \\
\hline 56) & 0 & 1 & No & No \\
\hline 57) & 0 & 5 & No & No \\
\hline 58) & 0 & 1 & No & No \\
\hline 59) & 0 & 22 & Sí & Sí \\
\hline 60$)$ & 0 & 7 & No & No \\
\hline 61) & 0 & 4 & No & Sí \\
\hline 62) & 0 & 20 & Sí & Sí \\
\hline 63) & 0 & 15 & Sí & Sí \\
\hline 64) & 0 & 21 & Sí & Sí \\
\hline 65) & 0 & 3 & No & No \\
\hline 66$)$ & 0 & 1 & No & No \\
\hline 67) & 0 & 8 & No & Sí \\
\hline 68) & 0 & 11 & No & Sí \\
\hline
\end{tabular}


Los datos más importantes que se derivan de la aplicación del cuestionario «Puntos de Vista» o «Atlacholoaya» son los siguientes:

1) El puntaje mínimo ofrecido es de 0 mientras que el puntaje máximo es de 33 .

2) La media es 14,1475 .

3) Con un punto de corte de 15, habría 28 internos que lo igualarían o superarían (23 de ellos aceptando los delitos cometidos y 5 de ellos sin aceptarlo).

4) El 41,18\% de la población tendría rasgos de personalidad y/o actitudes que predisponen al comportamiento delictivo violento.

5) Los sujetos restantes (40 internos, el 58,82\%) habrían delinquido debido, fundamentalmente, a factores circunstanciales y/o sociales más que por una inclinación psicológica a la criminalidad.

Haciendo una comparación entre la escala Atlacholoaya y el test de Millon, observamos que:

1) El porcentaje de sujetos antisociales registrados mediante la escala Atlacholoaya es del 41,18\% mientras que a través del test de Millon es del 45,6\% (31 sujetos), si bien hay que tener en cuenta que 9 de los 68 sujetos no realizaron o no completaron adecuadamente la prueba, de tal manera que entre quienes la completaron con éxito el porcentaje en la dimensión antisocial asciende al 52,5\%. A este respecto, hemos de tener en cuenta que en el MCMI-II se consideran como puntuaciones clínicas significativas aquellas puntuaciones directas que alcanzan o superan la Tasa Base (TB) de 75 (consúltese al respecto la tabla 2.21 que aparece en Millon, 1998b, p. 81), constituyéndose por tanto en líneas de corte que serían indicativas de trastornos de personalidad. 
2) Solamente 12 de los 68 internos (el 17,65\%) presentan puntuaciones dispares (esto es, puntuación antisocial en una prueba y puntuación prosocial en la otra) con respecto a las dos pruebas psicológicas aplicadas.

3) La correlación entre ambas escalas es de 0,672.

Por otra parte, y con el propósito de evaluar la consistencia interna de los diferentes ítems que componen la escala Atlacholoaya, se ha aplicado el coeficiente alfa $(\alpha)$ de Cronbach. El resultado obtenido ha sido de 0,928 , por lo que podemos afirmar que el grado de confiabilidad es elevado.

\section{Discusión}

El presente estudio exploratorio, consistente en la creación y aplicación en el medio penitenciario de tres nuevos cuestionarios, además de la aplicación del MCMI-II como prueba de contraste, se atiene al propósito principal de recabar información de ciertos sujetos que han sido acusados y procesados por la comisión de delitos violentos, de los que se pretende saber cómo piensan y perciben las relaciones con los demás y qué circunstancias o sucesos biográficos les caracterizan. En este sentido, los datos obtenidos a través de «Sucesos de la Vida» $\mathrm{y}$ «Actos Delictivos» nos ayudan a entender la incidencia de las relaciones familiares, la búsqueda de emociones fuertes, el uso de las drogas y el manejo de la culpa. Y a través de la escala Atlacholoaya, tal como anteriormente se ha puesto de manifiesto, se pueden detectar los elementos de personalidad que predisponen a la comisión de conductas delictivas y/o violentas.

En comparación con el MCMI, la escala Atlacholoaya tiene como fortalezas su especificidad (en tanto en cuanto está orientada exclusivamente a la evaluación de la personalidad antisocial) y su aproximación de campo (en tanto en cuanto se fundamenta en las frases expresadas durante un proceso de entrevistas en profundidad por varios reclusos de características psicopáticas). En cualquier caso, estamos refiriéndonos a una propuesta novedosa que podría resultar de gran utilidad si se la somete a sucesivas revisiones y ensayos. Algunas de las cuestiones a trabajar para su mejoramiento y apuntalamiento son las siguientes: 
1) Habría que inspirarse en los datos criminológicos, biográficos y relacionales que se han obtenido a través de los cuestionarios «Sucesos de la Vida» y «Actos Delictivos» para la formulación de nuevos ítems que ayuden a enriquecer el constructo de la personalidad antisocial.

2) Habría que revisar y reconsiderar, con una población mayor, algunos ítems que en el estudio piloto han quedado descartados. De los 114 ítems iniciales de que constaba la escala Atlacholoaya han sido seleccionados 39, quedando fuera del listado final (bien porque no correlacionaban lo suficiente con la dimensión antisocial del test de Millon o bien porque la Chi-cuadrado no era significativa) algunos ítems que se hubieran deseado incluir por ser interesantes desde un punto de vista teórico y también por tener un porcentaje de respuesta bastante elevado, tales como:

- Con la mayoría de las personas actúo de manera fría, con un corazón de hielo, suprimiendo los sentimientos (30,9\%).

- Soy capaz de aceptar y comprender que mi pareja esté hablando con otra persona $(33,8 \%)$.

- Me gusta demostrar a la gente que es muy diferente de lo que dice o aparenta $\operatorname{ser}(41,2 \%)$.

- Los seres malvados existentes en el mundo son minoría, son relativamente pocos $(43,3 \%)$.

- Las normas y leyes de la sociedad son una basura $(44,1 \%)$.

- Si trato mal a alguien es porque se lo merece $(44,1 \%)$.

- Por todo lo que yo he hecho, merezco que la vida me trate bien y ser, por tanto, afortunado $(44,8 \%)$.

- Me resulta difícil, por no decir imposible, llorar (48,5\%).

- Mucha gente trata de humillarme (58,8\%).

- Hay que estar continuamente alerta, preparado para responder a las agresiones (58,5\%).

- Soy capaz de controlar los remordimientos y la culpa $(63,2 \%)$.

- El mundo se encuentra tan mal que está próximo su final, el Apocalipsis (66,7\%). 
- Creo que las personas nos merecemos todo lo bueno y todo lo malo que nos pasa $(69,1 \%)$.

- El ser humano siempre trata de aprovecharse del prójimo (76,5\%).

3) Habría que aplicar la escala Atlacholoaya a una población mucho más amplia que la del presente estudio piloto para que finalmente la selección de los ítems y la distribución de los mismos conviertan al nuevo instrumento en una alternativa para la evaluación de la personalidad antisocial o psicopática.

4) Habría que formular y redactar nuevos ítems que discriminen certeramente el tipo de personalidad que se pretende medir, al mismo tiempo que inciten a un alto porcentaje de respuesta.

La presente investigación está lejos de poder constituirse en algo acabado; se trata de una aproximación inicial, de un estudio piloto, que eso sí arroja datos interesantes, con un instrumento (la escala Atlacholoaya) que cumple satisfactoriamente los criterios de fiabilidad y validez. En un futuro podría resultar de gran ayuda para detectar de entre los acusados y/o condenados por actos delictivos y/o violentos a aquellos que responden al perfil de personalidad antisocial o psicopática, lo cual tiene repercusiones importantes en la toma de decisiones judiciales, psicoterapéuticas, de rehabilitación y de reinserción social.

\section{AGRADECIMIENTOS}

El autor de este artículo da las gracias al subsecretario de readaptación social del Estado de Morelos, al director general de reclusorios, al director del CERESO de Atlacholoaya y a sus trabajadores, así como a todos y a cada uno de los 68 reclusos que participaron en la investigación. 


\section{Referencias bibliográficas}

Aluja, A. (1991). Personalidad desinhibida, agresividad y conducta antisocial. Barcelona: Promociones y Publicaciones Universitarias.

Amenabar, J. M. (2003). Violencia y criminalidad: una aproximación psicológica desde el caso «Oruan». En C. O. Barros (coord.), Violencia, Politica Criminal y Seguridad Pública (pp. 255-294). México: INACIPE.

American Psychiatric Association (2003). DSM-IV-TR. Manual diagnóstico y estadístico de los trastornos mentales. Barcelona: Masson.

Andreu, J. M., Peña, M. E. y Graña, J. L. (2002). Adaptación psicométrica de la versión española del Cuestionario de Agresión. Psicothema, vol. 14, nº 2, 476-482.

Ávila, A. (1997). Prólogo a la edición española. En T. Millon, MCMI-II. Inventario Clínico Multiaxial de Millon-II (pp. 5-7). Madrid: TEA, 1998.

Ávila, A. y Jiménez, F. (1998). Adaptación española del MCMI-II. En T. Millon, MCMI-II. Inventario Clínico Multiaxial de Millon-II. Madrid: TEA.

Caballo, V. E. y López Torrecillas, F. (2004). El trastorno antisocial de la personalidad. En V. E. Caballo (coord.), Manual de trastornos de la personalidad (pp. 109-135). Madrid: Síntesis.

Garrido, V., Stangeland, P. y Redondo, S. (1999). Principios de criminología. Valencia: Tirant lo Blanch.

Hare, R. (2000). La naturaleza del psicópata: algunas observaciones para entender la violencia depredadora humana. En A. Raine y J. Sanmartín (coords.), Violencia y psicopatía (pp. 15-58). Barcelona: Ariel.

Jiménez Gómez, F. y Sánchez Crespo, G. (2003). Evaluación psicológica forense. Salamanca: Amarú.

Lamprea, J. A. y Gómez-Restrepo, C. (2007). Validez en la evaluación de escalas. Revista Colombiana de Psiquiatría, vol. XXXVI, nº 2, 340-348.

López Miguel, M. J. y Núñez Gaitán, M. C. (2009). Psicopatía versus trastorno antisocial de la personalidad. Revista Española de Investigación Criminológica, artículo $1, \mathrm{n}^{\circ} 7,17$ páginas.

McCord, J. (2000). Contribuciones psicosociales a la violencia y la psicopatía. En A. Raine y J. Sanmartín (coords.), Violencia y psicopatía (pp. 207-233). Barcelona: Ariel. 
Miller, A. (1998). El saber proscrito. Barcelona: Tusquets.

Millon, T. (1998a). Trastornos de la personalidad. Más allá del DSM-IV. Barcelona: Masson.

- (1998b). MCMI-II. Inventario Clínico Multiaxial de Millon-II. Manual. Madrid: TEA.

Organización Panamericana de la Salud (2003). Informe mundial sobre la violencia y la salud. Washington, D. C.: Publicación Científica y Técnica No. 588.

Patrick, C. J. (2000). Emociones y psicopatía. En A. Raine y J. Sanmartín (coords.), Violencia y psicopatía (pp. 89-118). Barcelona: Ariel.

\section{Datos del autor}

José Martín Amenabar Beitia es doctor en psicología. Trabaja como profesor de tiempo completo en la Facultad de Psicología de la Universidad del País Vasco, concretamente en el Departamento de Personalidad, Evaluación y Tratamiento Psicológico. Sus principales áreas de interés son la delincuencia, el maltrato infantil y la violencia de pareja. 